\title{
Análisis de la distribución espacial de los RSU en la Zona Metropolitana de Tampico
}

\section{Analysis of the spatial distribution of RSU in the Tampico Metropolitan Area}

\author{
Raúl Treviño-Hernández* \\ Elda Margarita Hernández-Rejón* \\ Edel Cadena-Vargas** \\ Salvador Adame-Martínez**
}

Recibido: marzo 18 de 2019

Aceptado: agosto 23 de 2019

\begin{abstract}
Resumen
El objetivo de la investigación es elaborar una cartografía de la generación de residuos sólidos urbanos en la Zona Metropolitana de Tampico y observar su distribución espacial en el territorio, para, desde un punto de vista integral, tener el conocimiento de la situación actual que prevalece en la zona. Se aplicaron encuestas y se recolectaron los residuos en los hogares seleccionados, a fin de obtener la generación por día de la semana y su composición en una clasificación estándar que permitió elaborar la cartografía sobre la generación y composición de residuos en todas las zonas de la ciudad. Se concluye que la cantidad y composición de los residuos generados en los hogares se ve influenciada, en gran medida, por el ingreso del jefe de familia, así como por la cultura de las personas. El averiguar la cantidad y la composición de los residuos generados en un territorio es de suma importancia porque amplía el conocimiento del fenómeno y ayuda a explicar algunos problemas presentados.
\end{abstract}

Palabras clave: territorio, sustentabilidad, residuos.

\begin{abstract}
The objective of the research is to elaborate a cartography of the generation of solid urban waste in Tampico Metropolitan Area and to observe its spatial distribution in the Territory, from an integral point of view to obtain the knowledge of the present situation that prevails in the area .With the application of surveys and the collection of waste in selected households, the generation of waste per day of the week was obtained and the composition of it in an standard classification allowed the elaboration of the cartography on the generation and composition of waste in all areas of the city. It can be concluded that the quantity and composition of household waste is largely influenced by the income of the head of household, as well as by the culture of the people. The knowledge of the quantity and composition of the waste generated in a territory is very important because it expands the knowledge of the phenomenon, and helps to explain some problems presented, without this information, it is difficult to know.
\end{abstract}

Keywords: territory, sustainability, waste.

*Universidad Autónoma de Tamaulipas, México, **Universidad Autónoma del Estado de México, México.

Correos electrónicos: rtrevin@docentes.uat.edu.mx,mrejon@docentes.uat.edu.mx, ecadenav@uaemex.mx, sadamem@uaemex.mx 


\section{Introducción}

El objetivo de la investigación es elaborar una cartografía de la generación de residuos sólidos urbanos en la Zona Metropolitana de Tampico y observar su distribución espacial en el territorio, para, desde un punto de vista integral, tener el conocimiento de la situación actual que prevalece en la zona.

La preocupación progresiva por los efectos del crecimiento económico, por el desarrollo y la expansión de las áreas urbanas, así como por el actual modo de vida sobre el medio ambiente y la sostenibilidad ha propiciado la toma de conciencia sobre el problema de la gestión de los Residuos Sólidos Urbanos (RSU en adelante).

El inconveniente del manejo y la disposición final de los residuos en México se ha recrudecido en los últimos años debido al acelerado crecimiento demográfico, lo que se traduce como un incremento en los montos de residuos producidos que, además, presentan una composición más compleja y heterogénea (Restrepo et al., 1991). En México, la generación de residuos sólidos urbanos se ha incrementado de manera importante en las últimas décadas; según datos de SEMARNAT (2012), la generación a nivel nacional de RSU entre 1997 y 2011 creció 43.8\% con relación al volumen diario; entre 1950 y 2011 aumentó más de tres veces; es decir, en promedio 3.3 kilogramos por año. Sin embargo, las cifras a nivel nacional son estimaciones y no mediciones directas, lo que conlleva a cierta reserva con respecto a los datos a una escala local.

Es necesario estudiar el territorio, así como los cambios y las transformaciones, a fin de tener un mayor conocimiento y capacidad para interpretar la realidad pasada y presente $y$, sobre todo, para diseñar el futuro. A finales del siglo $\mathrm{XX}$, con el crecimiento de las actividades económicas basadas en el consumo, es decir, la cultura de usar y tirar, los problemas con los residuos empezaron a ser tangibles y preocupantes (UNED, 2003).

El nivel y tipo de vida, el grado de industrialización y la publicidad han propiciado en la sociedad actual un consumismo exagerado que origina un problema de contaminación provocado por la basura, dañando así el ambiente físico, social y biológico. La cantidad y el tipo de residuos sólidos tienen relación directa con la magnitud de la población, por lo que día a día avanza el problema. Por ello, es imperante plantear alternativas que deben ser estudiadas y aplicadas lo más pronto posible para conocer si son viables, rentables y benéficas para la comunidad. 
Las soluciones deben buscar proporciones óptimas de uso con los procedimientos disponibles. Entre ellos, básicamente, habrá que tomar en cuenta, en primer lugar, los destinados a la minimización de los volúmenes generados y al tipo de materiales desechados, pero, también, a la recolección y disposición final. Este último aspecto, se realizará mediante el reciclaje de residuos, así como la utilización de rellenos sanitarios y composteo de la basura que no pueda ser eliminada por otros medios (SEMARNAP, 1996).

Los residuos sólidos son aquellos desperdicios que no son transportados por agua y que han sido rechazados porque ya no se van a utilizar (Henry y Heinke, 1999). La gestión de residuos es el conjunto de actividades u operaciones encaminadas a dar a los residuos producidos en una determinada zona el destino más adecuado desde el punto de vista económico y ambiental (André y Cerdá, 2006).

La disposición final de los RSU es la parte más importante de todo el sistema de limpia, ya que presenta las mayores consecuencias y, por ende, implica un elevado costo, tanto económico como social. Durante los últimos años, en el Estado de Tamaulipas (México) y particularmente en los municipios de Victoria, Altamira, Tampico y Ciudad Madero se ha mostrado un desarrollo económico que no está acorde con el sistema actual de recolección, transporte, forma de manejo y disposición final de los RSU; por lo tanto, la propuesta y estudio de alternativas de solución es imperante bajo la perspectiva socioeconómica.

En México, según la Ley General del Equilibrio Ecológico y la Protección al Ambiente, para efectos de regulación y control, la federación se encarga de los residuos sólidos peligrosos (RSP), y al estado y municipio les compete lo relativo a los residuos sólidos no peligrosos (RSNP). Estos últimos se dividen, a su vez, en no peligrosos de tipo industriales (RSNPI) y urbanos (RSU) (NOM AA-91-1987, Secretaría de Gobernación). Esta investigación se enfoca al análisis de los RSU generados en el ámbito domiciliario y en lugares públicos. Ante la necesidad de eliminarlos, las autoridades llevan a cabo su manejo (NOM-CRP-001-ECOL-1993, Secretaría de Gobernación) que, conforme a la Ley General del Equilibrio Ecológico y Potencial Ambiental del estado de Tamaulipas (H. Congreso del Estado de Tamaulipas, 2016), incluye las etapas de recolección, transporte, reciclaje, almacenamiento, tratamiento y disposición final.

De esta manera, la situación de la disposición final de los RSU es un problema que requiere optimizar los recursos monetarios y naturales con que cuentan los municipios, eliminar los tiraderos a cielo abierto y crear proyectos que den soluciones coherentes y apegadas a la realidad. Por ejemplo, algunos estudios señalan que las ciudades fronterizas con Estados Unidos presentan los datos más elevados sobre generación de residuos sólidos en el país, teniendo hasta 1.048 kg/per cápita por día, contrastando con 0.697 $\mathrm{kg}$ / per cápita por día en el sureste mexicano (Rojas y Corona, 2008). 
Otro de los indicadores que cambian, de acuerdo con su ubicación geográfica, es el de composición de los RSU, ya que inciden diversos factores, como actividad económica de la localidad, patrones de consumo, cultura de la población, ingresos, entre otros. Se requieren estudios en torno a mediciones directas a escala local de la generación y composición de los RSU, a dimensión espacial y a la relación de estos elementos con otras variables que inciden en la generación de los residuos. Así, este artículo presenta un análisis espacio territorial de la generación y composición de los RSU por estrato socioeconómico, a través de cartografía elaborada con los datos obtenidos en la investigación.

El crecimiento urbano descontrolado, aunado a la falta de planificación, ha generado en México y en toda América Latina significativas inestabilidades territoriales, diferencias sociales, supresión de grupos, aumento de dificultades de habitabilidad de los espacios urbanos, así como otros inconvenientes, como: miseria; incertidumbre; congestión vial y habitacional; desempleo; diferencia ante el acceso a los bienes públicos; contaminación atmosférica, de la audición, paisajística y por residuos sólidos urbanos e industriales; ocupación anormal del suelo; inseguridad ante desastres, etc. (Hernández, 2010).

La Organización de Naciones Unidas (United Nations, 2000) advierte que, en el siglo XX, México, como muchos países latinoamericanos, ha sufrido un proceso de urbanización muy acelerado que ha provocado graves problemas de bienestar, seguridad y convivencia familiar y social. En este contexto, se han proyectado escenarios futuros para México, en uno de los cuales se prevé que para el año 2050 cuente con 132.2 millones de habitantes (68 personas/km2) (ONU, 2007), lo cual agravará aún más el problema de la generación de RSU y, por ende, su deficiente sistema de gestión integral.

El problema que se pretende analizar en la presente investigación es el aumento de la generación per cápita de RSU, lo que produce impactos ambientales, económicos y sociales negativos. Para el análisis de este fenómeno, no se deben ignorar los factores que inciden en la gravedad del problema, como los basureros clandestinos, los depósitos de basura a cielo abierto, la falta de recursos de las instituciones para llevar a cabo la gestión de los RSU. Para la gestión ambiental de RSU, es necesario disponer de información estratégica y actualizada que fundamenten el diseño de políticas para lograr el máximo mejoramiento del objetivo ambiental (minimización de residuos), para un gasto determinado de recursos (Field, 1995).

Sobre la cuestión de los residuos, se han hecho múltiples investigaciones. La mayoría son diagnósticos que describen la situación actual en diversos países. Sin embargo, se observa que antes del 2000 había pocas investigaciones sobre México y América Latina, y, después de esta fecha, han incrementado. 
La primera evidencia sobre los residuos se registra en Atenas en el 500 a. C., donde se adoptaron como medidas de eliminación la colección y el transporte; los mismos habitantes se encargaban de llevarlos a lugares en la periferia, a $1.5 \mathrm{~km}$ de distancia de los asentamientos. Posteriormente, en la época del Imperio Romano, el servicio de recolección se realiza de forma organizada y los residuos se recogían en pequeños vagones que tiraban caballos y se depositaban en zonas alejadas a la población; sin embargo, al caer este imperio, también decayó el sistema de recolección de residuos.

En 1855, después de una epidemia de cólera en Londres, Inglaterra, se llevaron a cabo diversos estudios sobre los problemas sanitarios que surgían en las grandes áreas urbanas. El doctor John Snow dirigió una de estas investigaciones y llegó a la conclusión de que el padecimiento se debía a la contaminación del río Támesis, pues ahí se arrojaban los residuos de las casas y de las industrias. Destacó que la única manera de eliminar las epidemias era mediante la mejora de las condiciones higiénicas de la ciudad. Esta experiencia fue el inicio de los estudios sobre el tema.

La gestión de los RSU se ha considerado una cuestión de ingeniería; por ello, la primera literatura, en su mayoría, fue de tipo tecnológico y ambiental. Sin embargo, los economistas desarrollaron algunos trabajos y hace algunos años esta perspectiva tomó más auge. "El problema de la gestión de residuos sólidos proviene de la falta de reconocimiento hacia la naturaleza económica del problema [...] esta situación está empezando a cambiar, pero el cambio ha sido demasiado lento para evitar la crisis actual" (Goddard, 1995). A continuación, revisaremos algunos de los estudios más relevantes, a decir del autor, sobre el tema.

A inicios de la década de los setenta, Alemania fue uno de los países europeos pionero en avances sobre el tema; dio un enfoque ambientalista a su política que se manifestó a través del decreto "Topfer". Este documento señalaba la importancia de la separación, prevención y reciclado de envases.

En la década de los noventa, en Europa, se percibió el problema de generación de residuos en ciertas épocas del año, como en vacaciones, cuando en algunos destinos turísticos la población aumentaba hasta el triple; también se percibió la falta de sitios para la disposición final de los residuos, por lo cual se inició la búsqueda de nuevas alternativas para resolver estas situaciones (Gasso y Baldasano 2000).

Como consecuencia de estas inquietudes, se realizaron investigaciones para el uso de tecnologías en la disposición de residuos; surgieron estudios a nivel piloto para determinar las propiedades estructurales, el comportamiento del $\mathrm{pH}$, la humedad, los compuestos orgánicos volátiles, biogás, los riesgos por inflamabilidad, entre otros (Ansbjer et al., 1995; Tamaddon et al., 1995; Sieger y Kewitz, 1997; Costemalle, 1997; Hogland, 1998; Robles y Goudon, 1999; Andreottola y Lagazzi, 2000; Andreottola et al., 2001). 
A mediados de la época de los noventa, en Suecia y Francia, surgieron los primeros estudios sobre la compactación y el embalaje plastificado de RSU. Costemalle (1997) y Sieger y Kewits (1997) analizaron la aplicación del almacenamiento temporal en placas impermeabilizadas; a este sistema se le conoce como "relleno seco".

En 2007, Nammari (et. al, 2007) estudiaron los compuestos orgánicos volátiles en el aire, que son emitidos durante el almacenamiento de los RSU en placas cilíndricas y rectangulares de diferentes densidades. En 2009, Tsagas (et. al, 2009) y otros realizaron estudios al relleno sanitario de Alexandroupolis en Grecia, con placas cilíndricas empacadas con LDPE a $770 \mathrm{~kg} / \mathrm{m} 3$, y observaron ausencia de lixiviados y olores. En 2010, la Asociación Interamericana de Ingeniería Sanitaria y Ambiental realizó un estudio de la Evolución Regional de Residuos Sólidos en América Latina y el Caribe, en donde presentan la generación de residuos sólidos urbanos para la región. Precisamente en América Latina, y particularmente en el caso de México, se han incrementado significativamente las investigaciones sobre el tema (OPS-AIDIS-BID, 2010).

Acurio (et. al, 1997), publican un trabajo editado por el Banco Interamericano de Desarrollo (BID) y la OPS, denominado "Diagnóstico de la situación del manejo de residuos sólidos municipales en América Latina y el Caribe", en el cual presentan los avances logrados en la región sobre la situación en el manejo de residuos sólidos municipales de ocho países: Argentina, Brasil, Chile, Costa Rica, México, Perú, Trinidad y Tobago, Venezuela, Guatemala, Colombia, Uruguay y México.

Particularmente, en México, existen muchos casos de investigación aplicados a la resolución de algún problema, como la tesis doctoral de Barradas en 1999 sobre una metodología adecuada a la planificación de la gestión integral de los residuos sólidos urbanos y rurales (aplicada a la zona Minatitlán-Cosoleacaque, en el sur de México (Barradas, 2009). Otra investigación doctoral es la de Velázquez (2006), “Gestión ambiental y tratamiento de residuos urbanos: propuesta para la zona metropolitana de Guadalajara a partir de las experiencias de la Unión Europea". Este trabajo presenta un interesante análisis comparativo sobre el problema de la generación y la gestión de los RSU. Los estudios al respecto son diversos: sobre los problemas urbanos de los RSU, las técnicas, las nuevas tecnologías, así como sobre las políticas públicas para la mejor gestión de RSU.

\section{Metodología}

La estructura metodológica parte de un método inductivo, que será transversal (en el tiempo) y correlacional (para las variables). Se evaluará la relación entre el nivel socio económico y la generación per cápita de RSU. La investigación comprenderá tres etapas. 
La primera se destina a la recolección de información general; para ello, se revisan estudios, textos, publicaciones oficiales, informes estadísticos y publicaciones electrónicas a través de Internet; así como entrevistas con especialistas en el manejo de residuos sólidos y visita a bibliotecas de instituciones relacionadas con el tema.

La segunda consiste en la preparación de materiales y equipos para la recopilación de datos en terreno. Algunos de estos materiales son: el diseño del cuestionario; la ficha de caracterización de RSU; el cálculo del tamaño de la muestra; la zonificación en cinco estratos socioeconómicos A, B, C, D, y E; y la aplicación de encuestas a una muestra representativa de la población objeto de estudio.

Por último, la tercera se trata del procesamiento e interpretación de los datos recopilados para identificar las acciones estratégicas a implementar en futuros Planes de Minimización de RSU. Principalmente, se evalúa el nivel de correlación entre las variables: generación per cápita de RSU, los factores socioeconómicos y la caracterización de los RSU (determinación del peso y composición por hogar) generados por la población muestra y la caracterización espacial mediante la elaboración de cartografía de la producción de RSU.

En resumen, se denomina generación de residuos a la cantidad de RSU que produce cada habitante por día; se estableció una división espacial de la zona de estudio con base en los estratos socioeconómicos; posteriormente, se determinó el tamaño de la muestra para la obtención de la información. A partir del muestreo de los hogares por estrato, se sistematizó y analizó la información para después realizar algunos cálculos estadísticos. Se obtuvieron datos sobre la generación de RSU por zona, por día de la semana y por estrato; y sobre la composición de los residuos. Finalmente, se trabajó con los datos utilizando un Sistema de Información Geográfica denominado Arc Gis. Se generó cartografía de los resultados y se obtuvieron 29 mapas, los cuales se consideran relevantes para el objetivo de la investigación.

\section{Resultados}

Como antecedente, podemos comentar que actualmente se generan 2,997 toneladas por día de basura en Tamaulipas, de las cuales: 24\% (716 ton./día) corresponde a la zona de Tampico, Ciudad Madero y Altamira; 16\% (493 ton./día), a Matamoros; 13\% (390 ton./día), a Nuevo Laredo; 21\% (640 ton./día), a Reynosa; 9\% (243 ton./día), a Cd. Victoria; y 17\% (515 ton./día), al resto de los municipios del estado.

La generación per cápita para la región sur de Tamaulipas es de 930 gr, lo cual se traduce en 716 ton/día; es la segunda región que tiene una mayor cantidad de residuos respecto al resto de las regiones (INEGI, 2010). Respecto a la proyección de toneladas generadas en cada municipio, se estima que, para el 2023, se incremente a un $8 \%$ en todos los municipios (CONAPO, 2010.) 
En cuanto a la composición de RSU, el mayor porcentaje corresponde a residuos orgánicos (53\%); le siguen los inorgánicos reciclables (32\%) y otros (15\%), papel y cartón en promedio en la zona sur de Tamaulipas.

Respecto a la recolección de residuos, sólo el municipio de Tampico cuenta con barrido mecánico y manual; se efectúa con una frecuencia de 6 días de la semana excepto los domingos y cubren casi la totalidad de las principales avenidas de las cabeceras municipales. El volumen de residuos recolectados en la región es de 694 ton/día, lo que representa el 97\% del total de residuos generados en la región. De acuerdo con la población atendida, la cantidad de residuos recolectados en cada municipio fue: Tampico, 287 ton; Altamira, 212 ton; Ciudad Madero, 195 ton.

Los municipios se encargan de recolectar los residuos generados en su territorio; no se cobra este servicio. La región cuenta con un total de 81 vehículos de recolección, distribuidos en los municipios de Tampico, Ciudad Madero y Altamira, pues tienen una mayor población. Además, la frecuencia del paso de los camiones recolectores por las zonas de recogida es diaria; se dice que tienen 178 rutas establecidas en total, aunque carecen de evidencia.

Sólo existe una estación de transferencia (ET), ubicada en el municipio de Tampico, en el sitio conocido como el Zapote. Los residuos son trasladados al Relleno Sanitario Regional Zona Conurbada, localizado en el municipio de Altamira. No se realiza ningún tipo de tratamiento a los residuos recolectados en la región. Existen cuatro sitios de disposición final (S.D.F.); se calcula que se depositan 694 ton/ día de RSU. Uno de los sitios es un relleno sanitario (R.S.) y se encuentra en el municipio de Altamira, conocido como "Zona Conurbada", y beneficia también a Tampico y a Ciudad Madero; dos son tiraderos a cielo abierto (T.C.A.) y son operados por personal del municipio; el otro es un T.C.A. sin operar (SEMARNAT, 2010).

La disposición final de los RSU en la ZMST es sin duda el principal problema en la gestión de los residuos sólidos en la zona. Sólo la ciudad de Altamira cuenta con un relleno sanitario que cumple con las normas establecidas para este fin. El sitio donde se depositaban los residuos sólidos municipales de la ciudad de Tampico, Tamaulipas, era un tiradero a cielo abierto denominado "Isleta del Zapote"; se encuentra rodeado por los vasos lacustres de la laguna del Chairel. Como en este lugar se había depositado la basura por alrededor de 25 años sin ningún control, es evidente que todos los escurrimientos de lixiviados van directamente a dichos vasos o canales de la laguna. Además, los camiones recolectores, tanto privados como del Ayuntamiento, descargan la basura sin seguir ningún procedimiento en el frente de trabajo. Al fondo se observan las torres de alta tensión de la Comisión Federal de Electricidad (CFE), cuyos cables cruzan el basurero a cielo abierto. Sin embargo, la situación es más grave, pues esta laguna es la que abastece la potabilizadora Alta Vista, la cual suministra agua potable a Tampico y a Ciudad Madero. 
El municipio de Ciudad Madero, localizado también en el sector Sur del Estado de Tamaulipas y que forma parte del área metropolitana, cuenta con un tiradero a cielo abierto (TCA), con una extensión territorial de 10 hectáreas, y en el cual se vierte la basura sobre la laguna. Esto la ha rellenado con el paso del tiempo; además, en la periferia existen asentamientos humanos lo cual intensifica el problema.

Actualmente, el municipio de Tampico ha contratado a la empresa privada TECMET para la recolección y el tratamiento de los Residuos Sólidos Urbanos, que son depositados en el municipio de Altamira, en el relleno sanitario, ubicado en Medrano. Como se ha podido comprobar, Tamaulipas padece fenómenos de degradación ambiental, por lo que es necesario tomar medidas urgentes que permitan crear conciencia entre la población de los riesgos ecológicos con los cuales convivimos y que ellos mismos demandan su solución. De manera tradicional, se ha puesto más énfasis en la regulación de la administración de los servicios de limpia que en el manejo seguro y ambientalmente adecuado de los residuos.

Por la forma en que se ha regulado la generación, el manejo y la disposición final de los residuos de jurisdicción local, no se ha logrado una gestión sustentable; es decir, ambientalmente efectiva, socialmente aceptable y económicamente viable. En términos generales, se ha observado, durante los últimos años, una leve mejoría en las condiciones de la gestión de los residuos sólidos urbanos; sin embargo, todavía se tienen deficiencias.

En Tamaulipas se han dado algunos pasos, aunque es necesario perfeccionar e incorporar algunos elementos al proceso, como el separado, el reciclaje, la mejora en la disposición y el tratamiento, la optimización de la imagen pública de la gestión de los residuos, entre otros, con el fin de lograr el cuidado, la protección y la restauración del entorno urbano. En general, muchos municipios de la República Mexicana no cuentan con áreas destinadas adecuadamente para el vertido y la disposición final de los RSU que cumpla con la normatividad dispuesta.

\section{Generación de RSU en la Zona Metropolitana del Sur de Tamaulipas}

El mapa 1 muestra la generación promedio de RSU en toda la zona de estudio, la cual se obtuvo a partir del muestreo de basura generado por hogar, por cada día de la semana. Se pueden observar las áreas marcadas de rojo que representan el rango más alto de cantidad de residuo generado, seguidas por las áreas de color naranja, amarillo, verde y azul, que corresponden a rangos menores. Se advierte que la zona con mayor cantidad de residuos generados es la zona centro, seguida de la zona sur, y, finalmente, la zona norte; esto se podría explicar debido a la alta concentración de comercios, restaurantes y bares, así como a la ubicación de los mercados municipales en la zona centro, lo que genera un flujo constante de personas y mayor actividad económica y, por ende, mayor generación de residuos. 
Mapa 1. Generación promedio de RSU en la zona de estudio

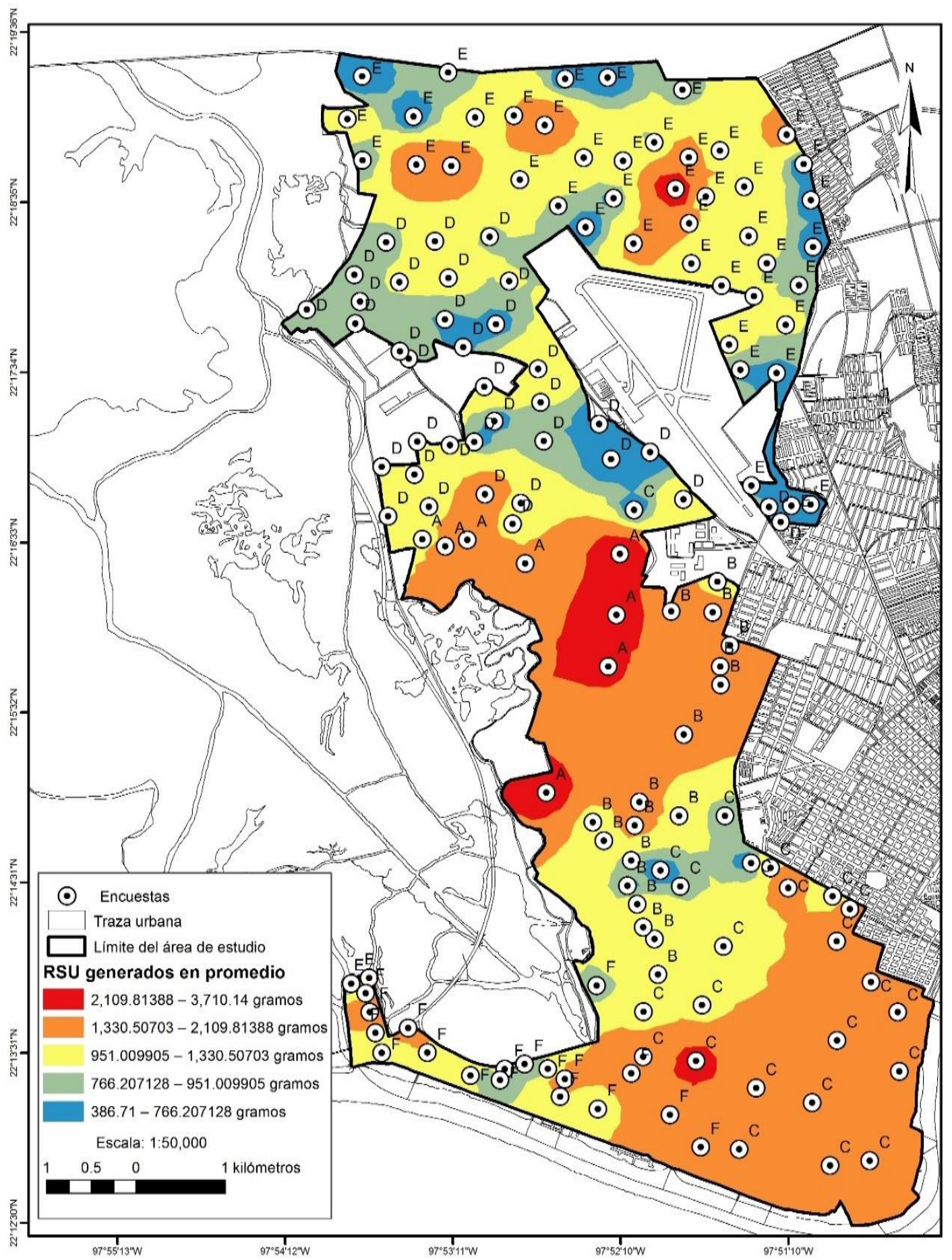

Fuente: elaboración propia con datos de los resultados de las encuestas 2017.

Los siguientes mapas muestran la generación de RSU por día de la semana en el territorio de estudio, así como importantes diferencias en cuanto a la generación de RSU por zona y por día. 
El mapa 2 indica la generación de RSU en domingo; se observa que ese día se generan más RSU, y que se vuelve a concentrar la mayor generación de residuos en la zona centro. Asimismo, un cambio notable es el incremento de la generación de residuos en la zona norte del territorio.

Mapa 2. Generación promedio de RSU en domingo en la zona de estudio

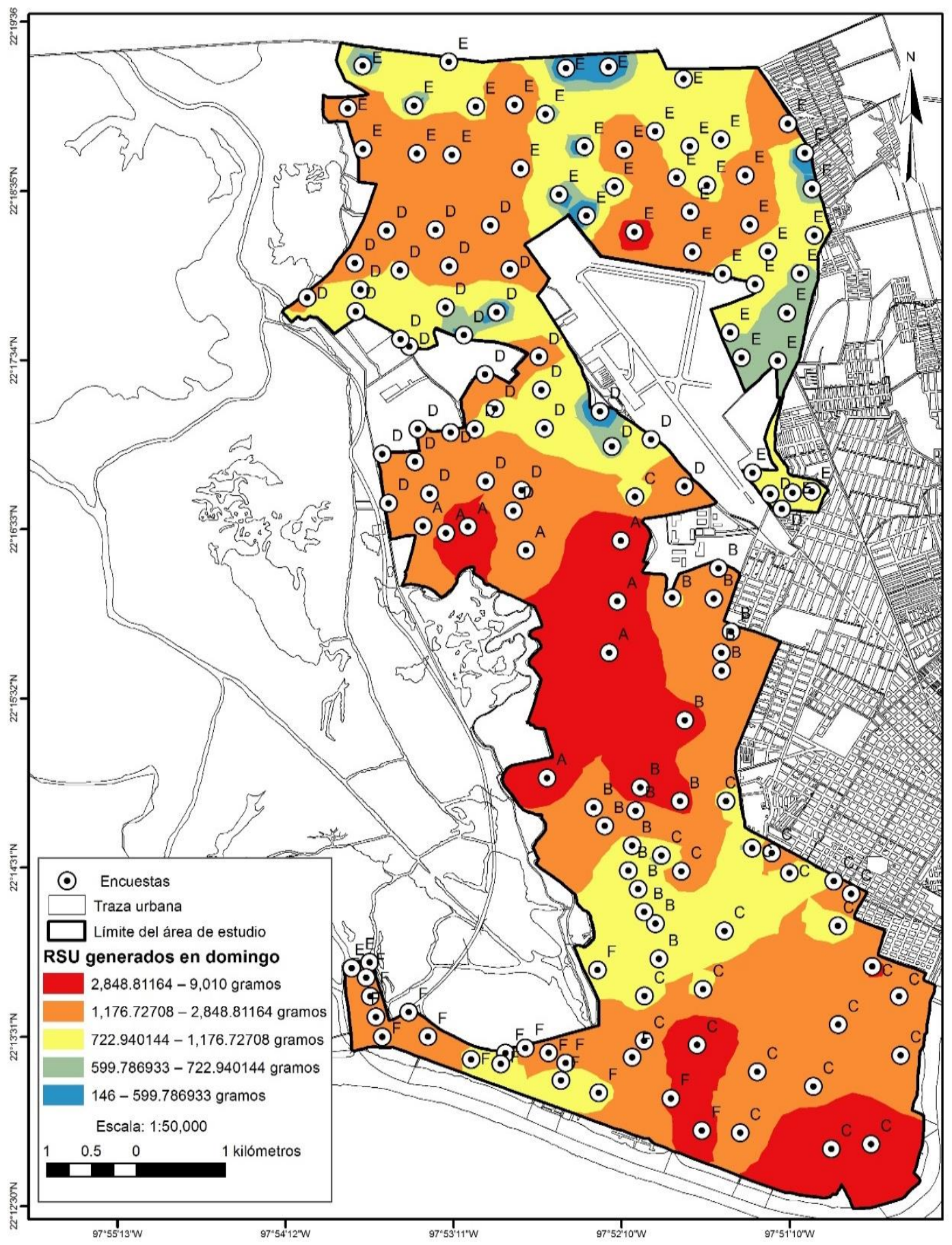

Fuente: elaboración propia con datos de los resultados de las encuestas 2017. 
El mapa 3 muestra la generación de residuos para el sábado. Se observa que la generación de residuos disminuye; el rango máximo es casi nulo y está representado con el color rojo. Sin embargo, se indica que, a pesar de la disminución de basura, la zona norte sigue generando la mayor cantidad.

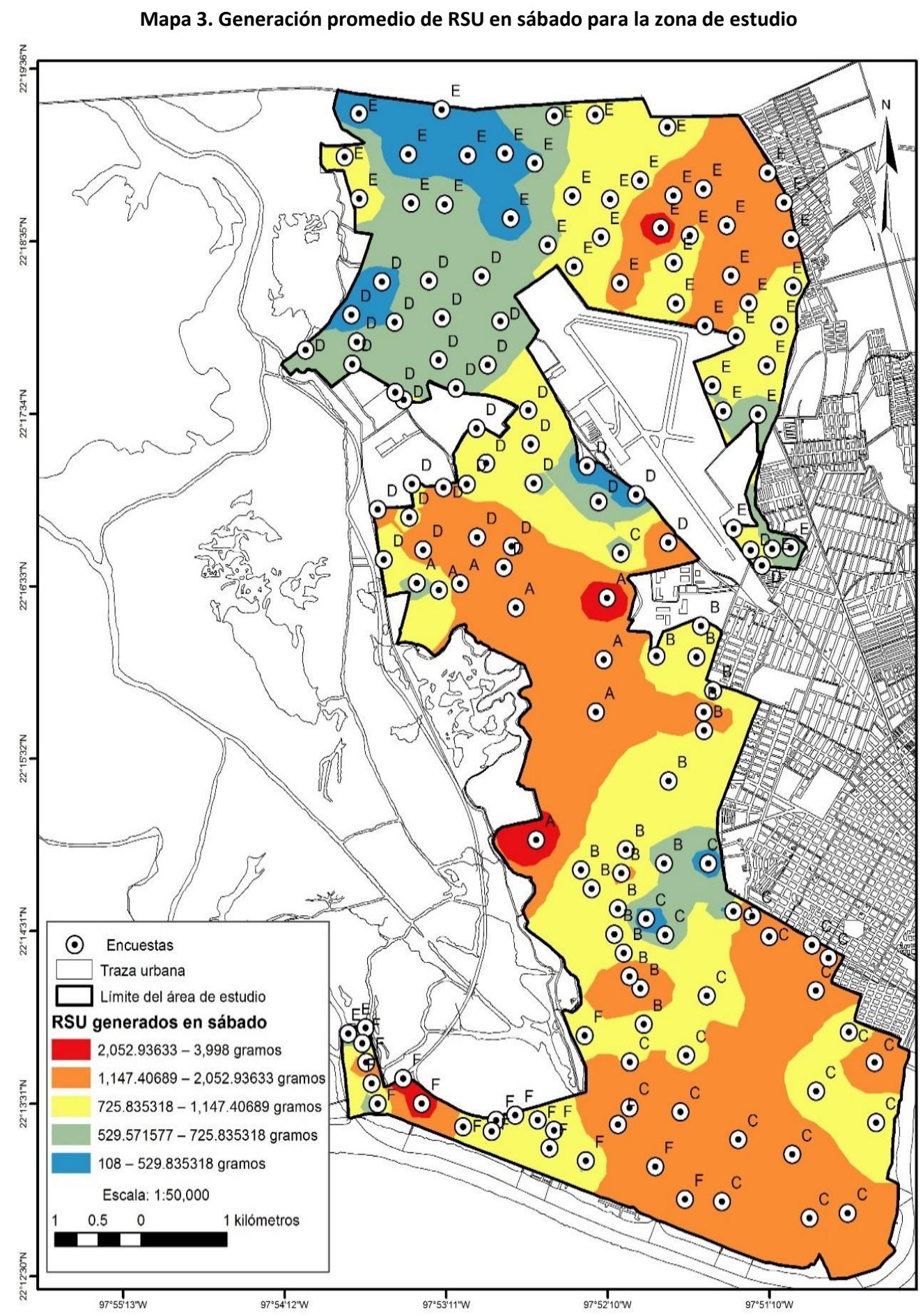

Fuente: elaboración propia con datos de los resultados de las encuestas 2017. 
El mapa 4 muestra los resultados para el día viernes, y se observa el mismo patrón de días anteriores para las zonas centro y sur; sin embargo, para la norte se percibe un ligero aumento en la generación de RSU.

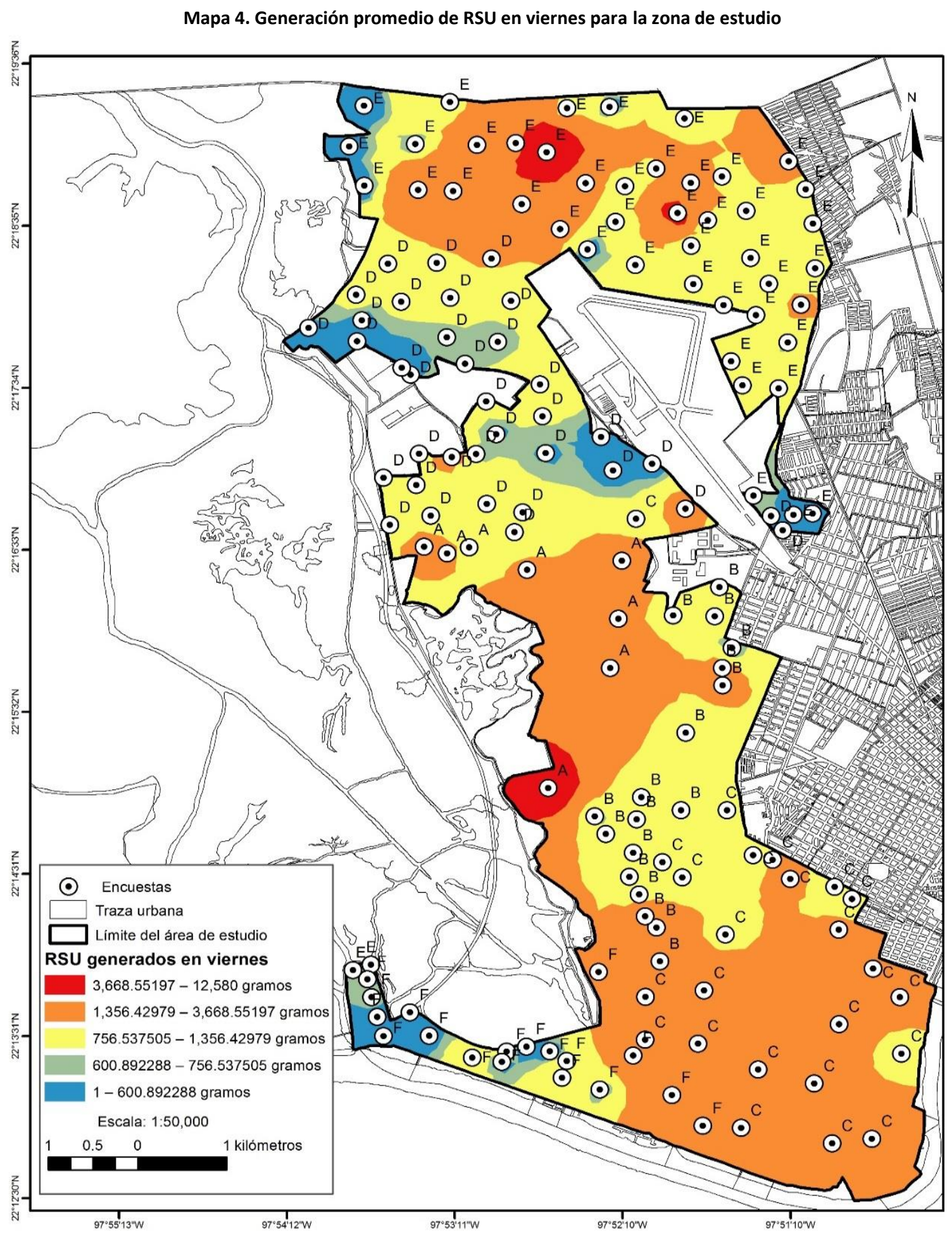

Fuente: elaboración propia con datos de los resultados de las encuestas 2017. 
En el mapa 5, se presentan algunos cambios significativos en la generación de residuos: en dos áreas de la zona norte del territorio aumentó la generación promedio, y en la zona sur hay un incremento considerable.

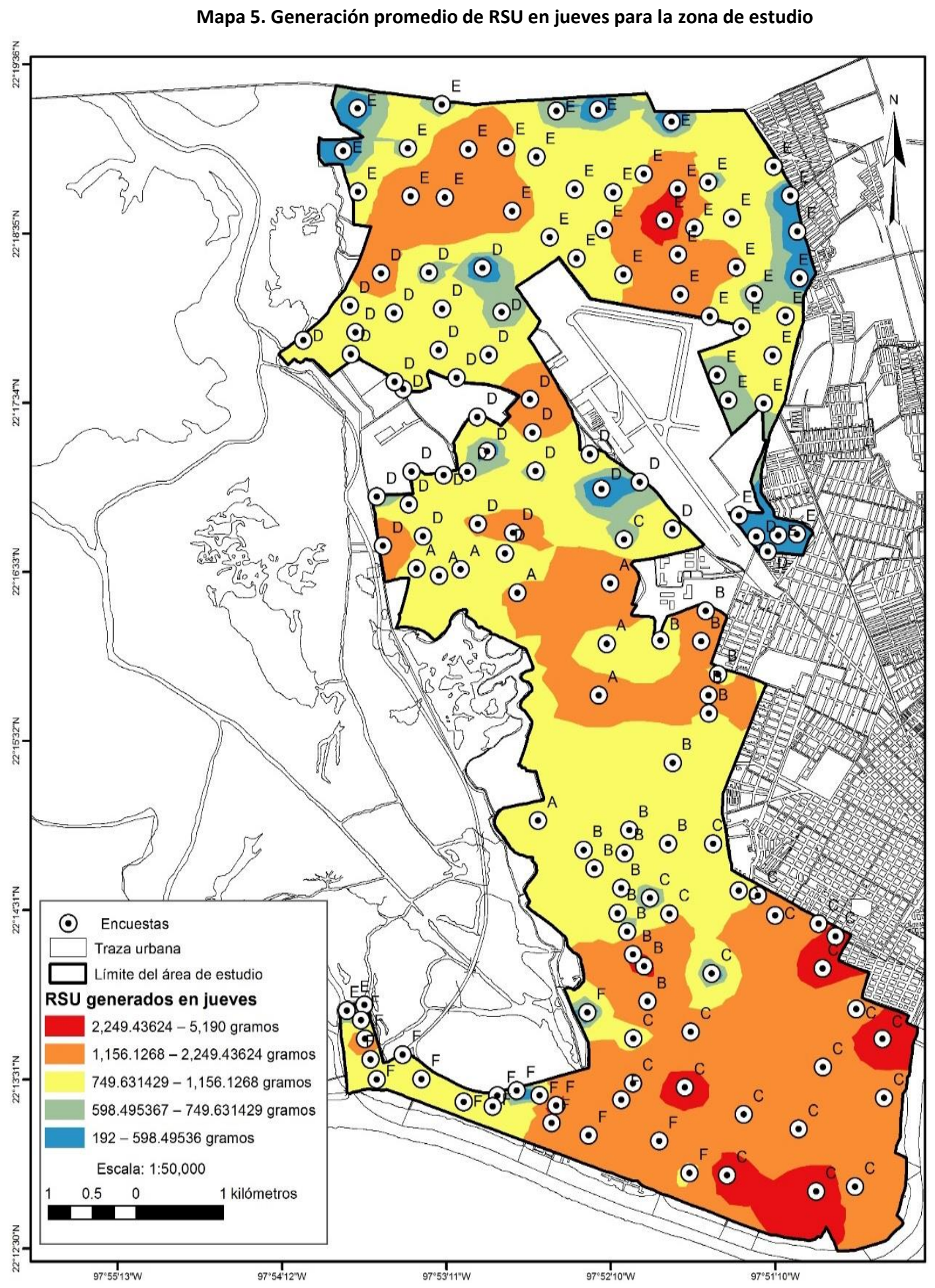

Fuente: elaboración propia con datos de los resultados de las encuestas 2017. 
En el mapa 6 se observa que nuevamente la mayor generación de RSU se concentra en la zona centro, así como en la zona sur del territorio, teniendo ésta, además, áreas críticas.

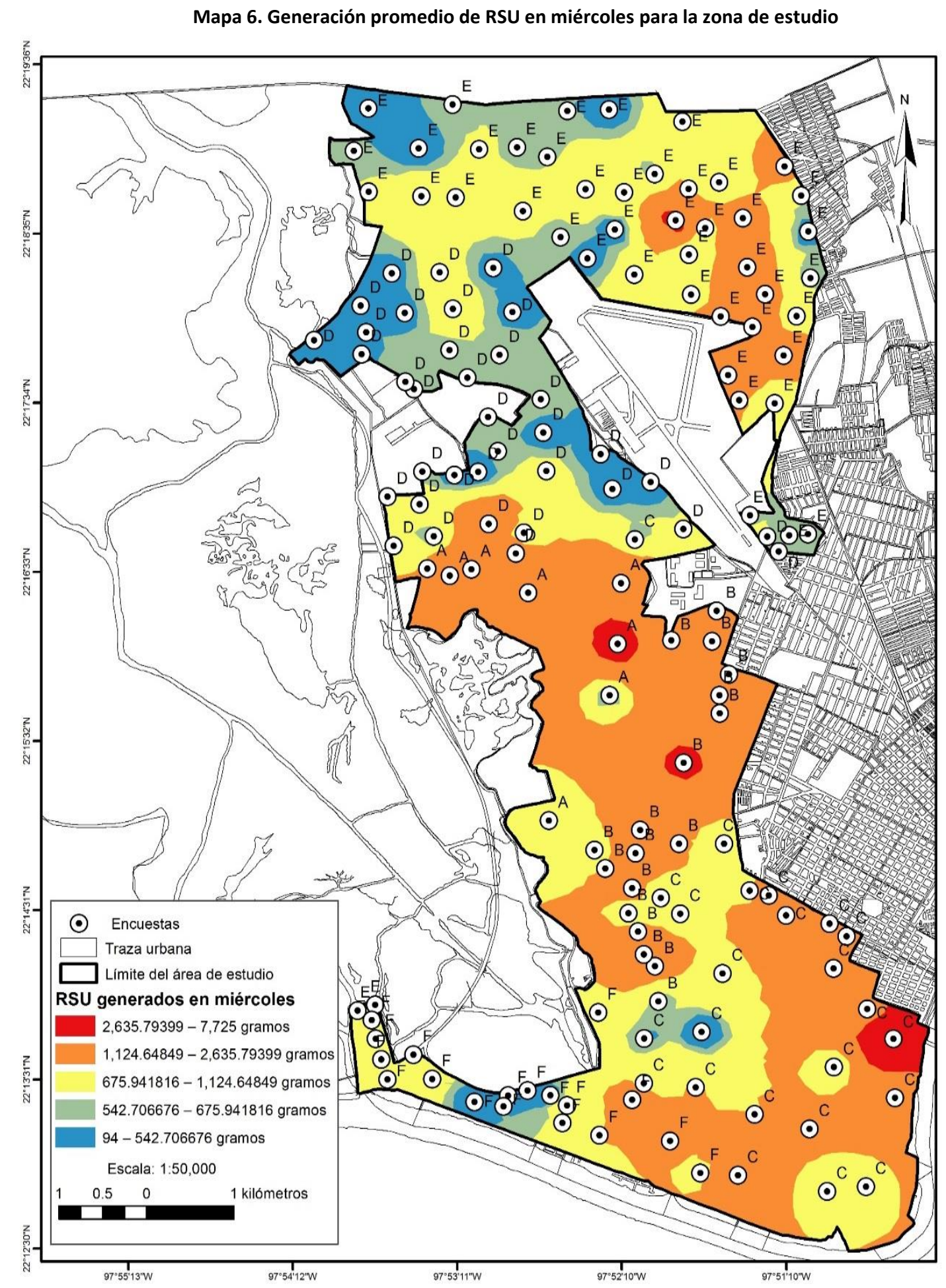

Fuente: elaboración propia con datos de los resultados de las encuestas 2017. 
El mapa 7 muestra el patrón promedio presentado; es decir, la mayor cantidad promedio generada de RSU está concentrada en las zonas centro y sur, en contraste con la zona norte que mantiene el mismo nivel de generación.

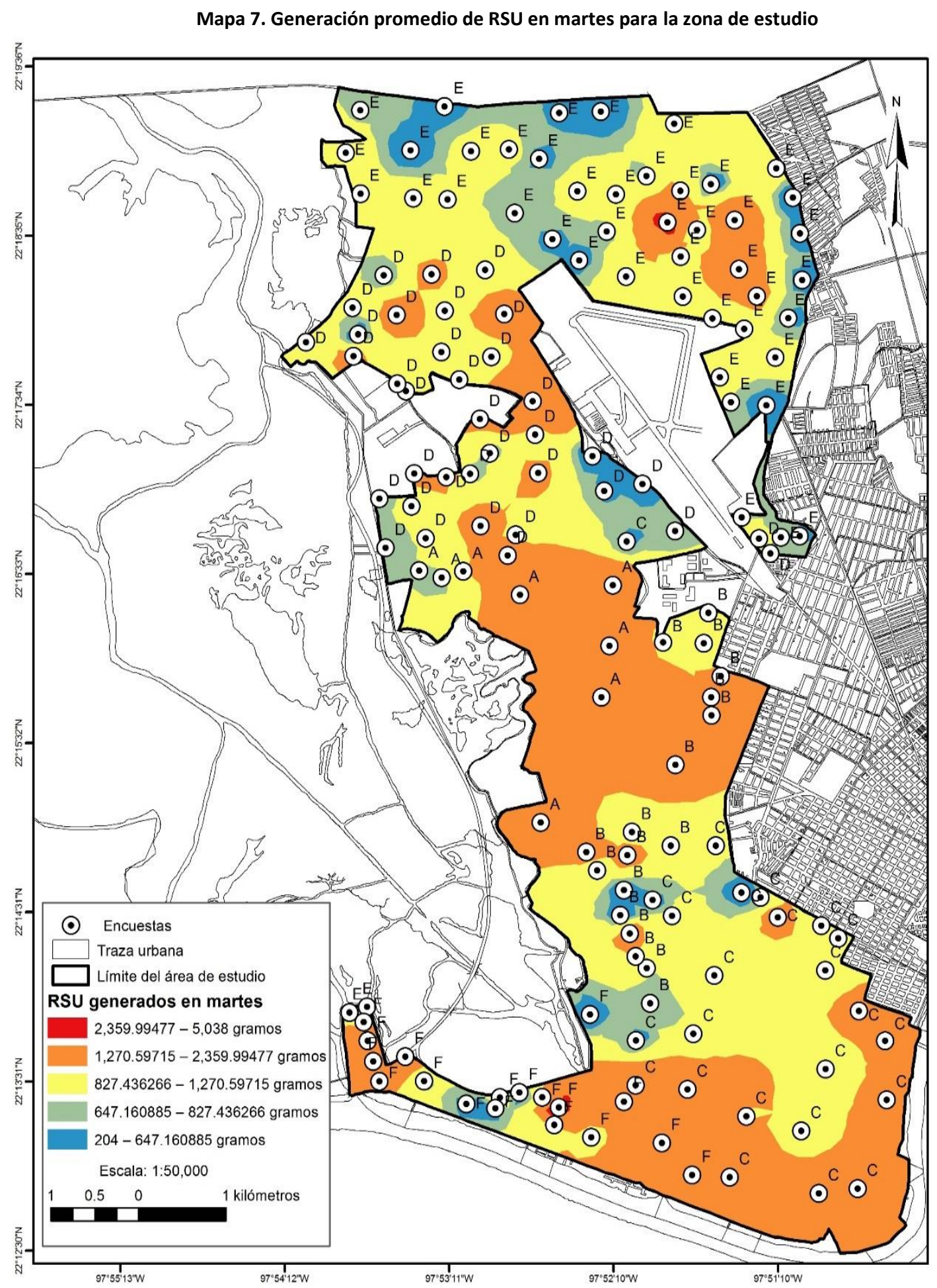

Fuente: elaboración propia con datos de los resultados de las encuestas 2017. 
El mapa 8 muestra los resultados para el día lunes; en general, se mantiene el patrón de mayor generación concentrada en la zona centro, siguiendo la sur, y con menor cantidad de basura generada en la norte.

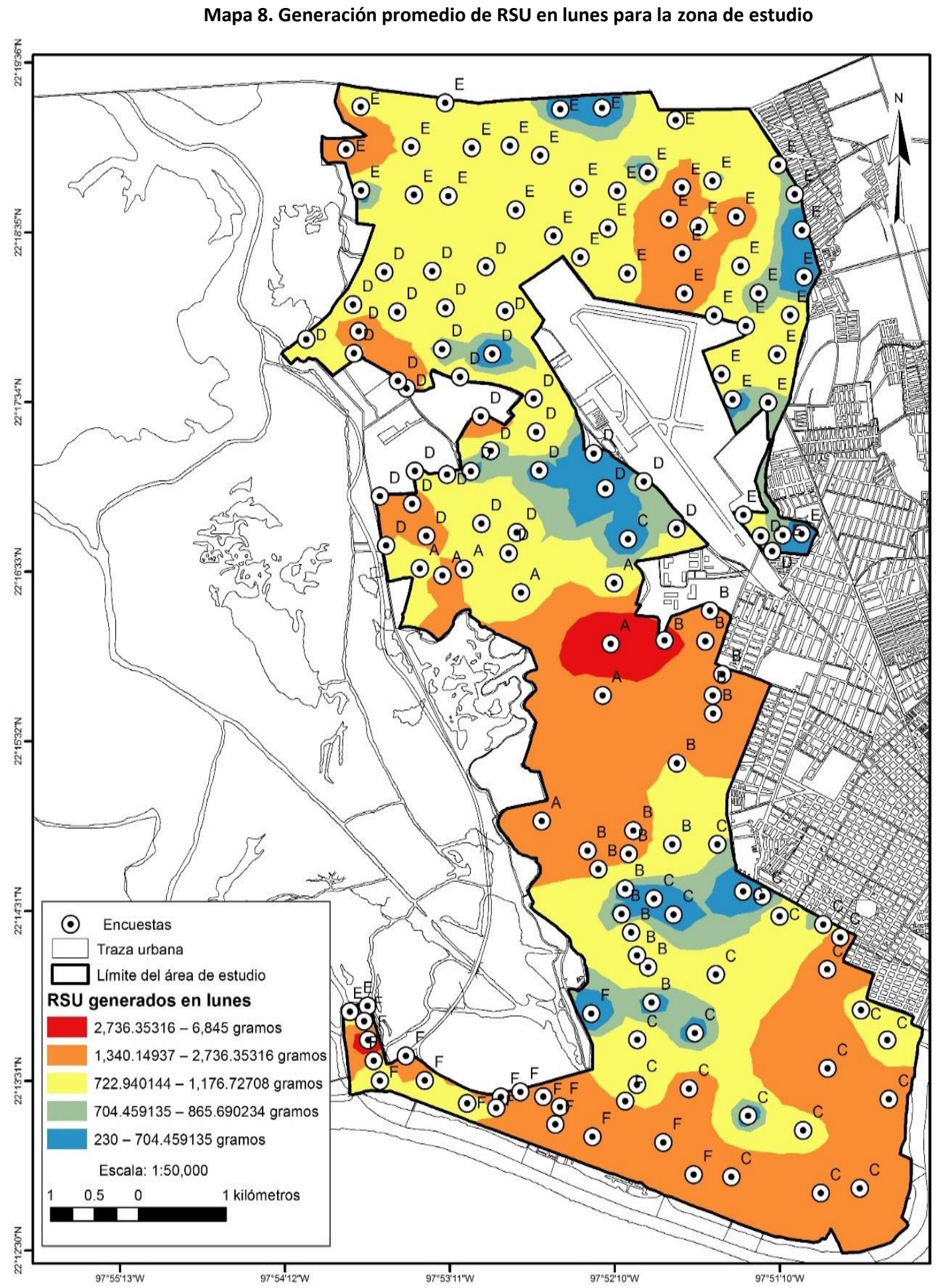

Fuente: elaboración propia con datos de los resultados de las encuestas 2017. 


\section{Clasificación por tipo de Residuos Sólidos Urbanos en la ZMST}

En este apartado se muestra espacialmente la generación por tipo de residuo en la ZMST, la cual se obtuvo del muestreo realizado a cada hogar, en donde de manera manual los residuos se separaron, se clasificaron y se pesaron todos los días durante el periodo de análisis. En primer lugar, se presenta un mapa general de generación de residuos según su tipo y después de cada uno de los residuos en todo el territorio. Esta información resulta importante para implementar una estrategia de recolección de residuos según su tipo y zona del territorio en donde más se generan.

En el mapa 9 se muestran los resultados espacio territoriales de la generación de residuo de acuerdo con su tipo y asignando un color: materia orgánica, plástico, vidrio, papel, textil, hueso, escombro y metal.

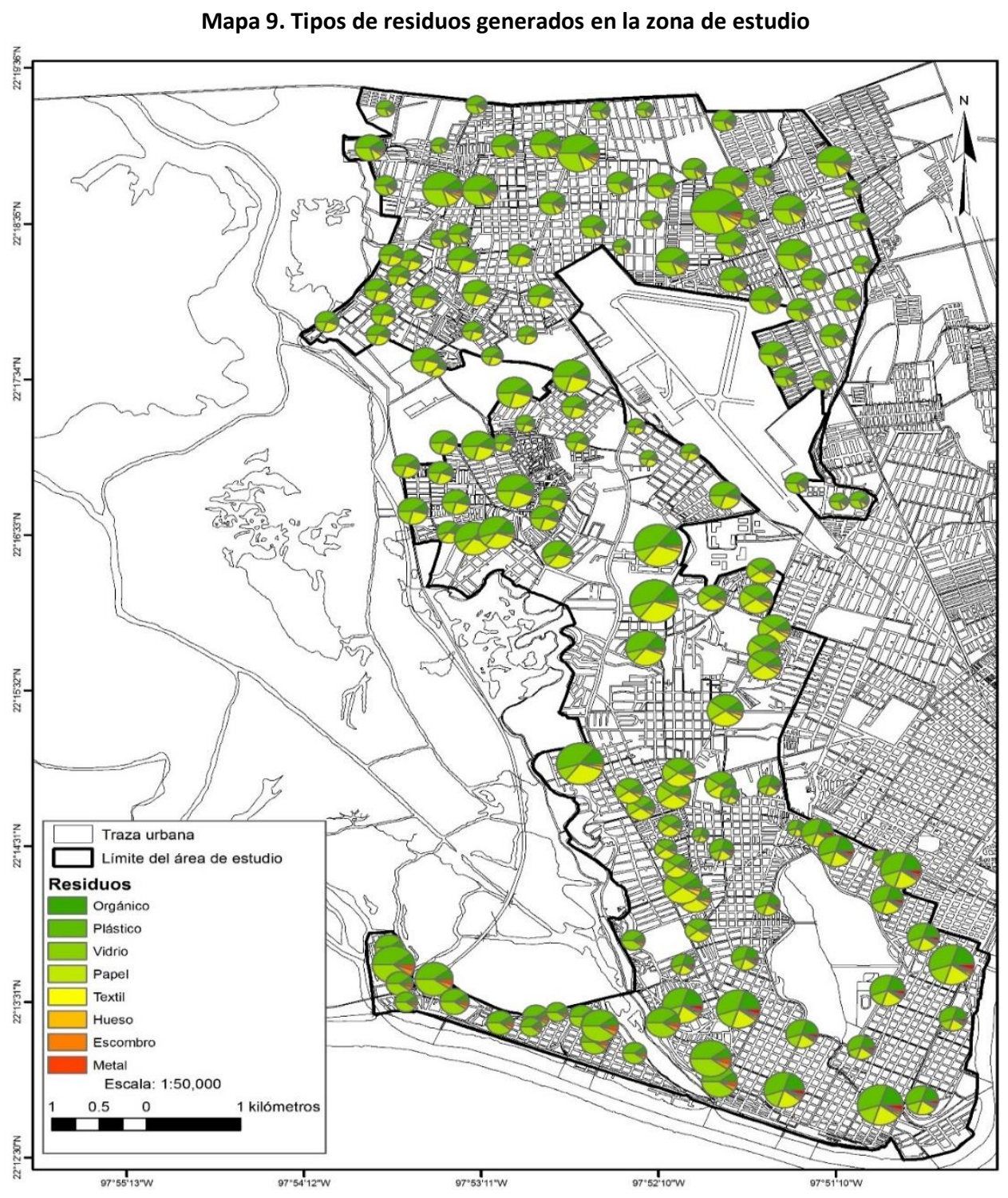

Fuente: elaboración propia con datos del muestreo de residuos por hogares 2017. 
En el mapa 10 se observa la generación de residuo orgánico y su ubicación espacial; la mayor generación se presenta en la parte sur y en el centro del polígono; en la zona centro se ubican los hogares con mayor nivel de ingreso, lo cual no necesariamente significa que gastan más en alimentos, pero el resultado demuestra que son los hogares que más alimentos desperdician.

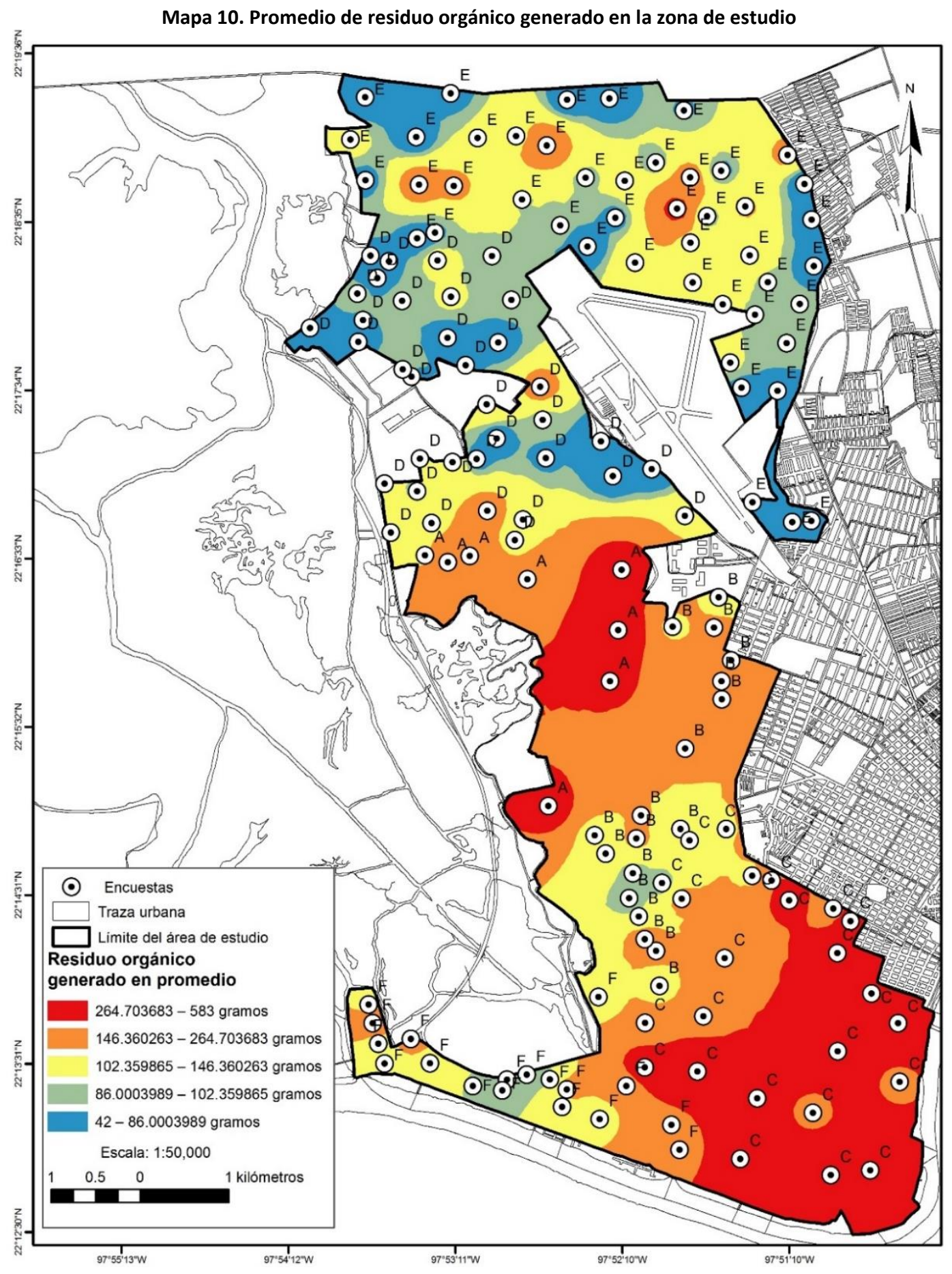

Fuente: elaboración propia con datos del muestreo de residuos por hogares 2017. 
El mapa 11 muestra el promedio de residuo plástico generado; se aprecia algo similar al mapa anterior. En el centro del polígono se concentra una alta generación de este residuo, seguido por la parte sur del polígono, lo cual se explica porque al centro se ubican los hogares con mayores ingresos, lo que implica un mayor gasto en productos con empaque, desechables, etc.

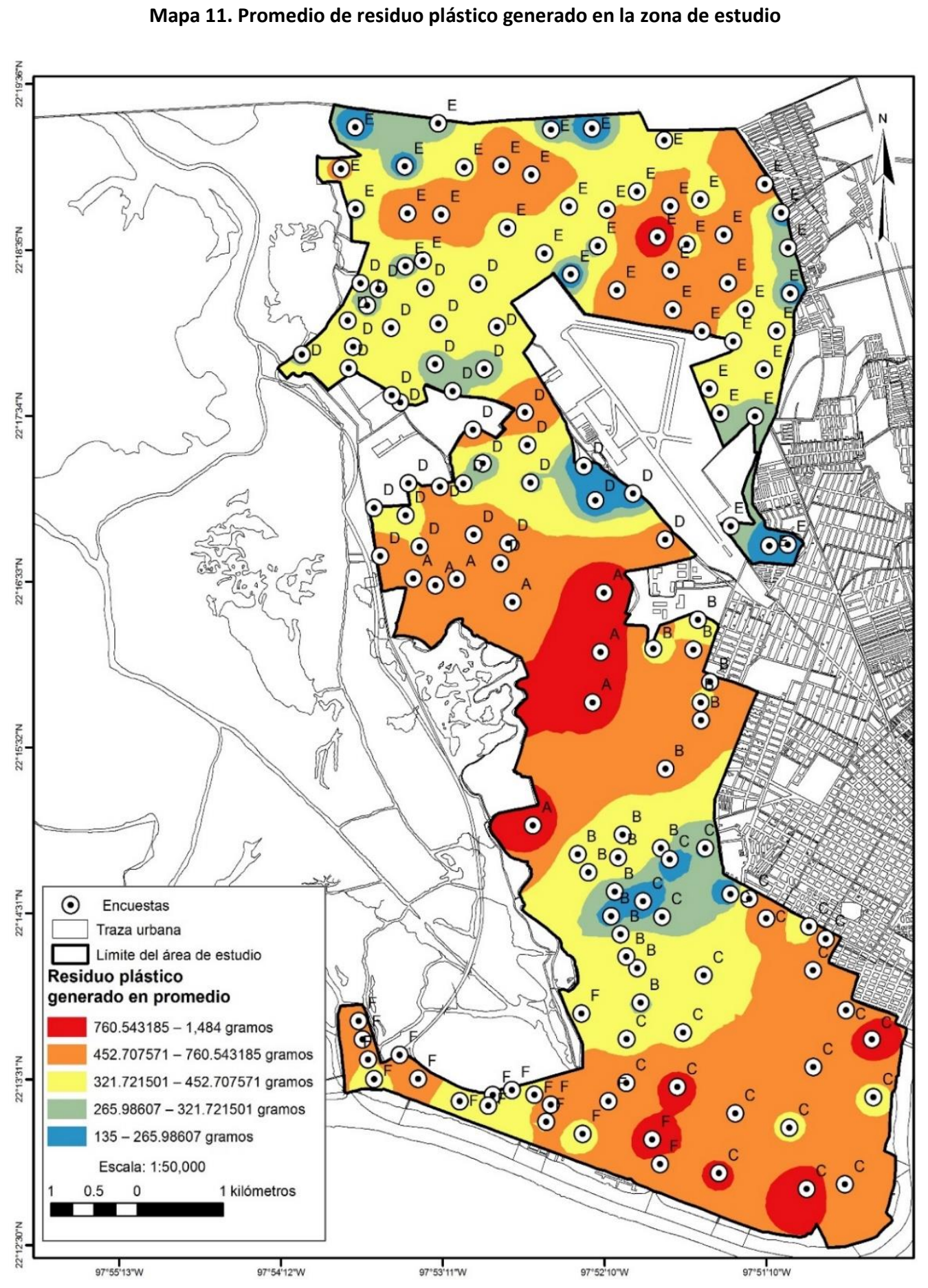

Fuente: elaboración propia con datos del muestreo de residuos por hogares 2017. 
En el mapa 12 se muestra el promedio del residuo vidrio generado y se observa que éste se encuentra en los rangos medio y bajo de generación en la zona. La mayor generación se concentra en la parte norte del polígono, en donde se ubican los hogares con menores ingresos económicos; una explicación es que en los hogares con menores ingresos se consume más refresco embotellado que desechable.

Mapa 12. Promedio de residuo vidrio generado en la zona de estudio

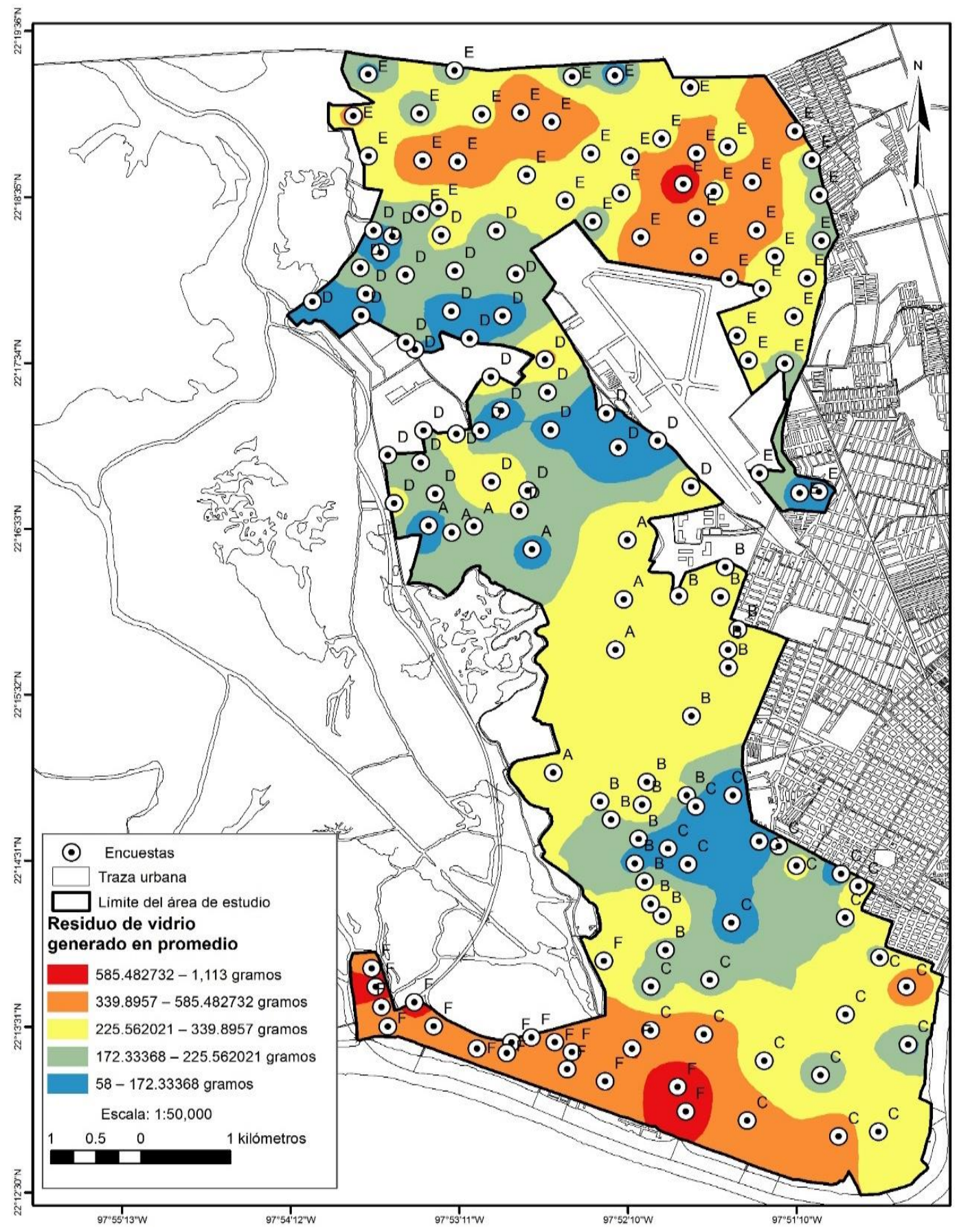

Fuente: elaboración propia con datos del muestreo de residuos por hogares 2017. 
En el mapa 13 se indica el promedio de papel generado. Se muestra que este residuo se genera en casi todo el territorio en cantidades similares o dentro del mismo rango. No sólo se presenta en las áreas como el centro, sino también en el área del norte; y en el suroeste, se observa la menor generación de este residuo.

Mapa 13. Promedio de residuo papel generado en la zona de estudio

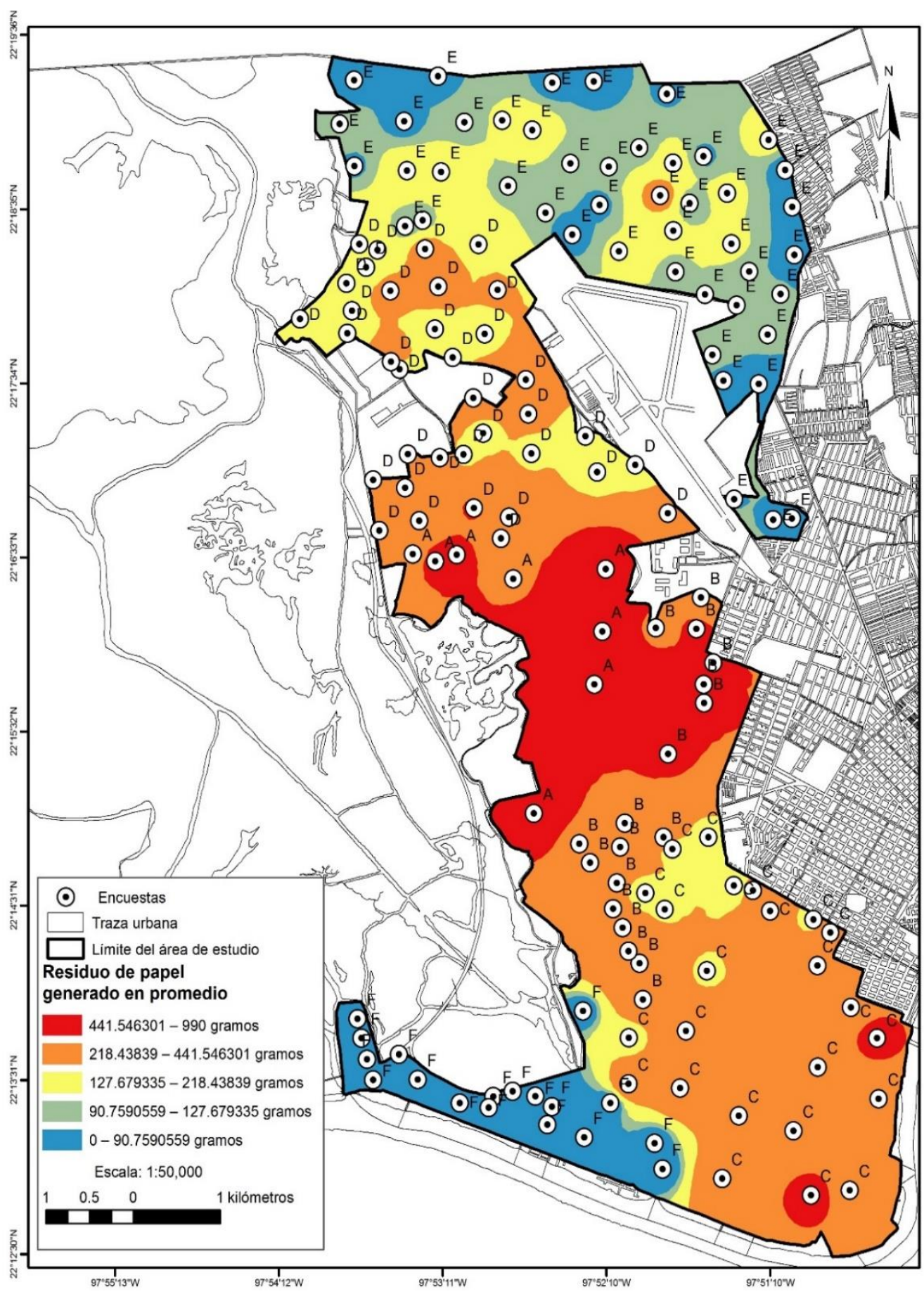

Fuente: elaboración propia con datos del muestreo de residuos por hogares 2017. 
En el mapa 14 se señala el promedio de generación de textil; este residuo es ropa; aunque se manifiesta en casi toda la zona, en el área central del polígono es donde se muestra la mayor generación, que es donde se ubican los hogares con mayor ingreso. En contraste, en el área sur del polígono se presenta la menor cantidad de residuo textil; zona donde se ubican los hogares con menor ingreso.

Mapa 14. Promedio de residuo textil generado en la zona de estudio

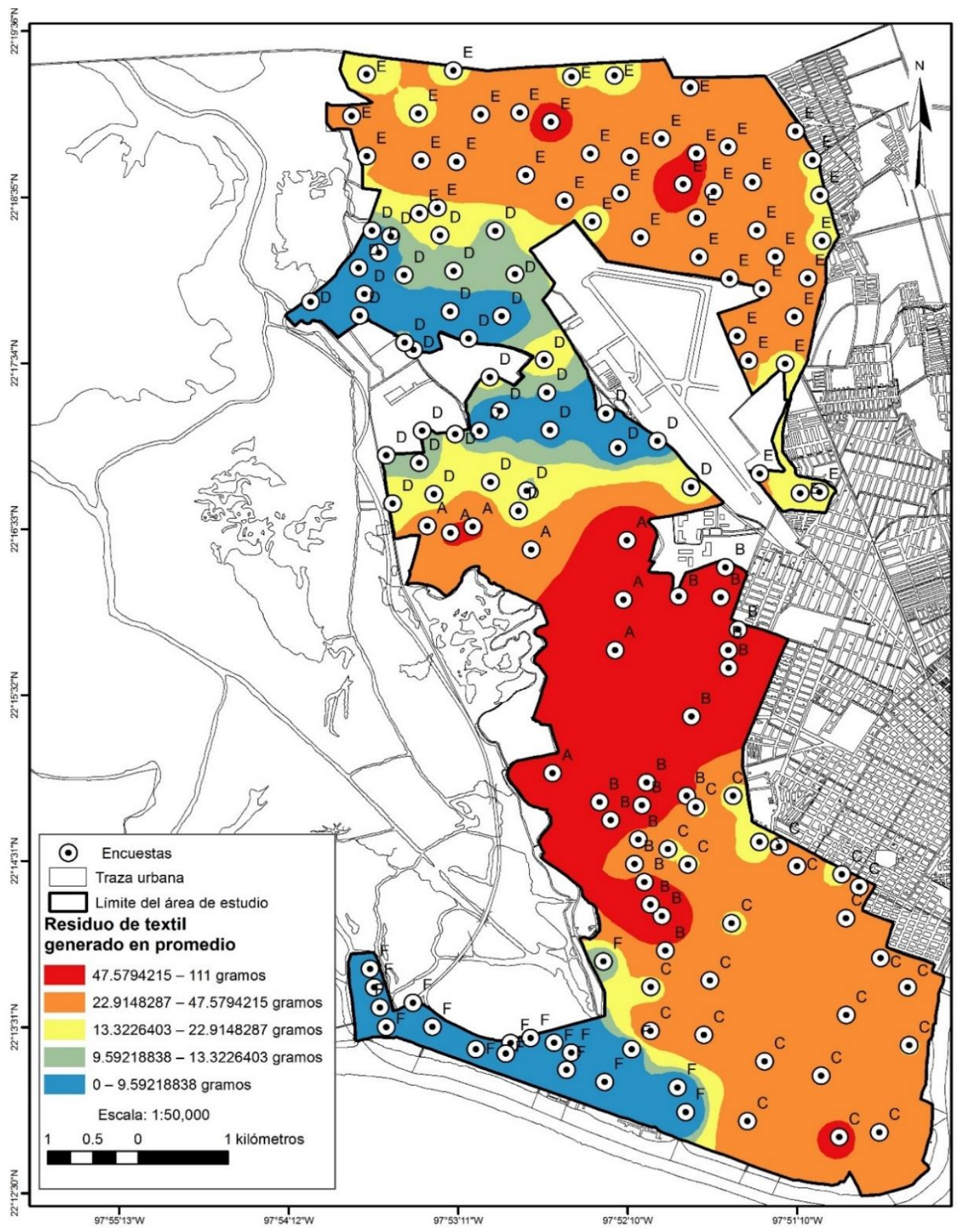

Fuente: elaboración propia con datos del muestreo de residuos por hogares 2017. 
En el mapa 15 se muestra que la generación de residuos de huesos no es muy alta; sólo se manifiesta en la parte centro del territorio, donde el nivel económico es alto; y en una parte de la zona norte del territorio, donde se encuentran los hogares con menos ingresos, pues, al estar ubicados en la margen del río, se dedican a la pesca y los huesos son producto de ésta.

Mapa 15. Promedio de residuo huesos generado en la zona de estudio

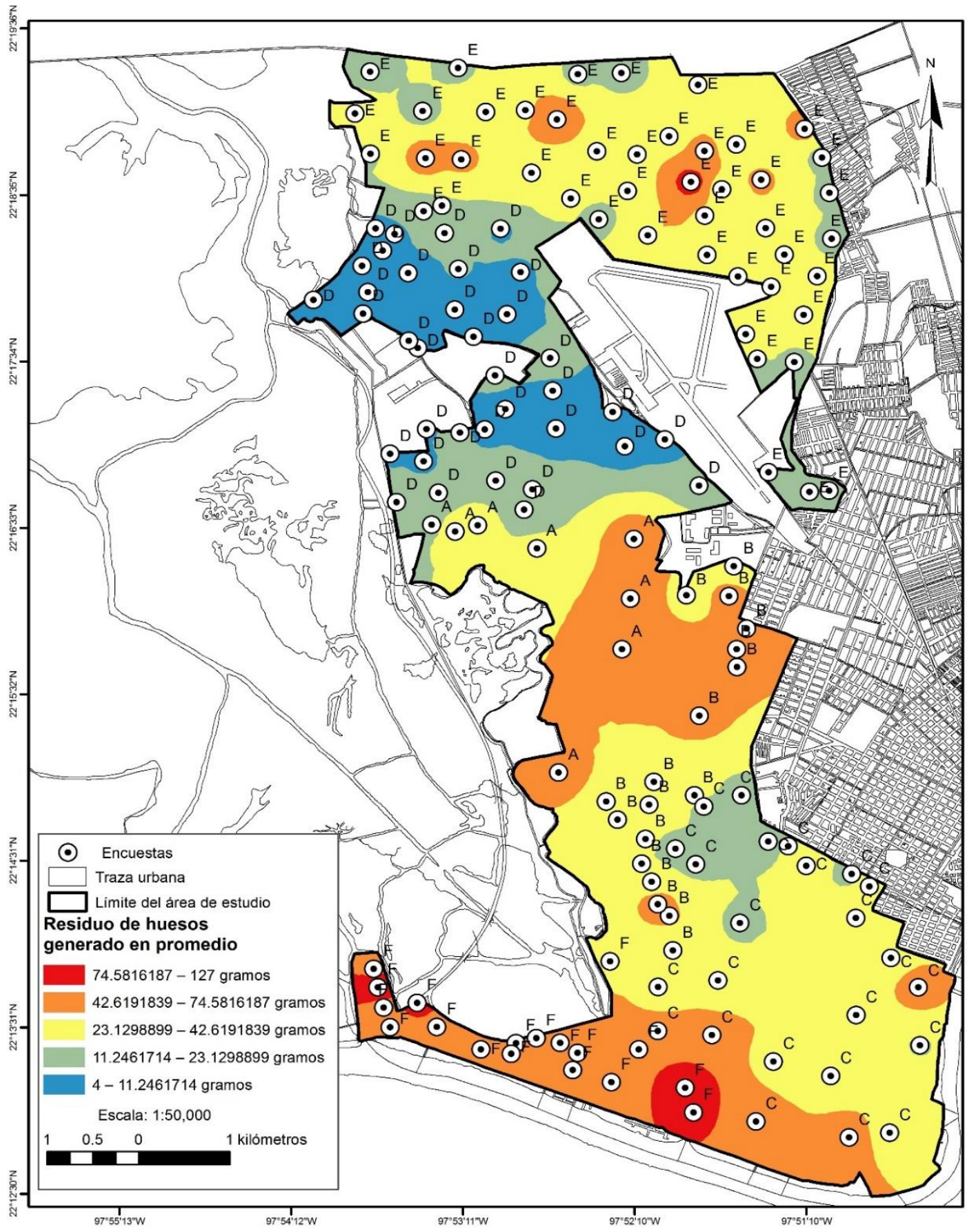

Fuente: elaboración propia con datos del muestreo de residuos por hogares 2017. 
En el mapa 16 se muestra la generación del residuo escombro en la zona de estudio. Se observa que, a lo largo del territorio, su generación no es muy significativa, pues existe reglamentación al respecto por parte de la Dirección de Obras Públicas. Las viviendas de nivel bajo están en continua construcción; las de nivel alto, si llegan a hacer algo, se encargan de retirar el escombro inmediatamente.

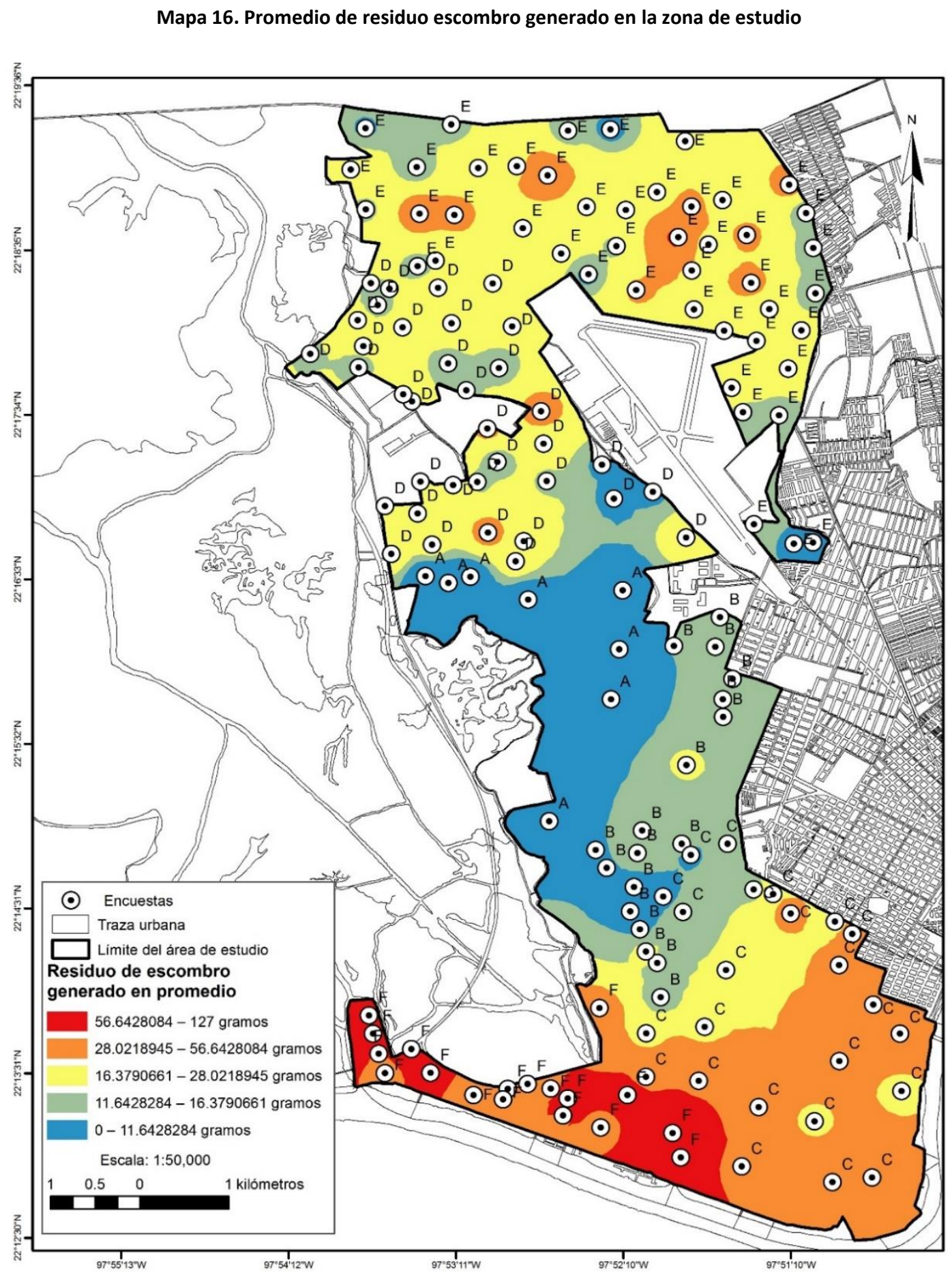

Fuente: elaboración propia con datos del muestreo de residuos por hogares 2017. 
En el mapa 17 se muestra la generación de residuo de metal, la cual, en general, casi no se presenta. En las áreas de menores ingresos, no hay generación de este residuo porque en la ZMT existen establecimientos que compran todo tipo de metales por kilo; y en estos estratos lo juntan (o pepenan); incluso, también, en otras partes del territorio para venderlos.

Mapa 17. Promedio de residuo metal generado en la zona de estudio

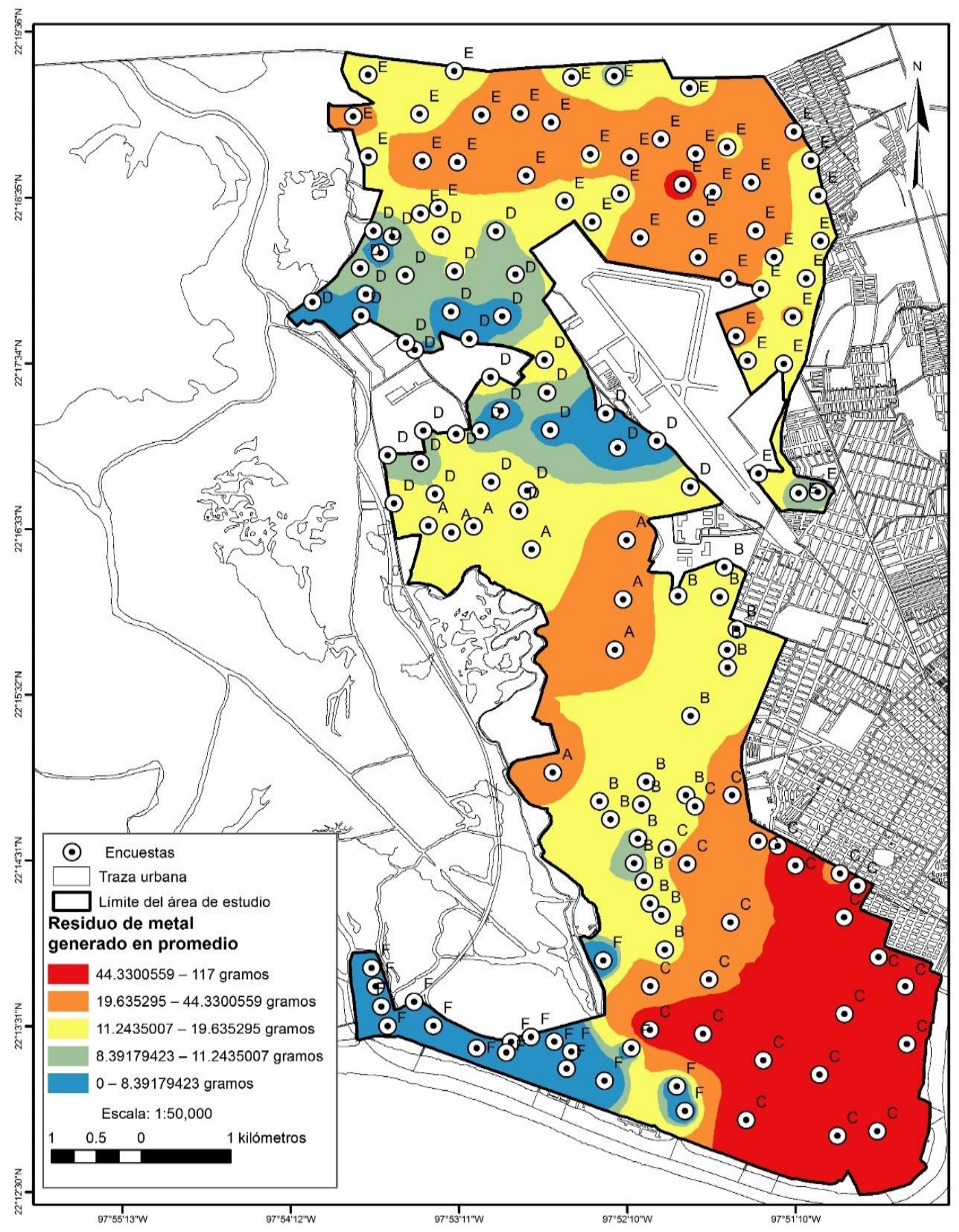

Fuente: elaboración propia con datos del muestreo de residuos por hogares 2017. 


\section{Discusión}

De los mapas anteriores, podemos observar que en la zona norte disminuye la generación de basura, concentrándose la mayor cantidad en el oriente, debido, principalmente, a que desde el 2013 es insuficiente la cantidad de camiones recolectores en la zona sur. De acuerdo con información publicada por el diario García (2013), en la ZM, había un parque total de 48 camiones recolectores para dar servicio a 616 colonias; 10 pertenecientes al municipio de Ciudad Madero, 10 de Altamira y 28 de Tampico; por lo que había un déficit de 120 toneladas que no alcanzaban a ser recogidas, sobre todo en los días intermedios; aunado a las fallas mecánicas de los camiones.

Además, los resultados presentados demuestran que las dos primeras partes del proceso de gestión de los residuos sólidos urbanos no funcionan de manera correcta, pues la generación es excesiva y variable en cuanto a cantidad; producto de la falta de cultura y sensibilidad de la población con respecto de los problemas ambientales, así como a la carencia de programas institucionales para promover la minimización de residuos.

En cuanto al proceso de recolección, es evidente que existen fallas importantes al no contar con la infraestructura y el equipamiento necesarios para realizar el trabajo; además, se carece de un plan estratégico de recolección y de una adecuada organización logística de las rutas con base en la cantidad de generación por zonas, con el fin de satisfacer la demanda existente. En este sentido, la presente investigación será de gran utilidad para identificar las rutas críticas de acuerdo con la mayor generación de residuos por zona y por días, lo cual sirve de base para el desarrollo de un plan estratégico de recolección diferenciada.

\section{Conclusiones}

Los residuos plásticos son los que más se generan en todas las zonas de la ciudad; por ello, es importante analizar la factibilidad de instalar recicladoras de plástico, ya que este tipo de residuo tarda mucho tiempo en degradarse naturalmente. Asimismo, en el análisis espacial de los resultados se observó que existen áreas del territorio en donde se incrementa de manera considerable el residuo vidrio, el cual, al igual que el plástico, requiere de un manejo especial; además, es imperante implementar estrategias para minimizar su generación y fomentar su reciclaje.

Otro hallazgo es que el papel o cartón se genera en todas las zonas del territorio y en cantidades significativas, lo cual tiene implicaciones de seguridad, ya que es flamable. Este residuo ocupa mucho espacio en los camiones recolectores y en gran medida podría evitarse su generación si existieran establecimientos o programas para su compra venta.

En el caso del metal, al existir sitios dedicados a su compra, se entiende que en el territorio su generación no sea significativa. En lo que se refiere al residuo orgánico, sólo se encontró que su generación aumenta a medida que asciende el nivel de vida; esto se explica porque, al haber mayor poder adquisitivo, se genera mayor desperdicio de alimentos. Por último, se observa que los residuos con menos presencia en las zonas de la ciudad son el textil, el escombro y los huesos. 


\section{Referencias}

Acurio, G., Rossin, A., Fernando, P. y Zepeda, F. (1997). Diagnóstico de la situación del manejo de residuos sólidos municipales en América Latina y el Caribe. Washington, D.C.: Banco Interamericano de Desarrollo y la Organización Panamericana. Recuperado de: https:// publications.iadb.org/es/publicacion/15925/diagnostico-de-la-situacion-del-manejo-deresiduos-solidos-municipales-en-america

Andre, F.C. y Cerdá E. (2006). Gestión de residuos sólidos urbanos: análisis económico y políticas públicas. Cuadernos Económicos De ICE, 1(71). Recuperado de http://www.revistasice.com/index.php/CICE/article/view/5880

Andreottola, G. y Lagazzi, M. (2000). "MSW Baling as a Pre-Treatment to Waste to Energy Plants" en: dell'Ambiente CIPA (eds). Innovation in Waste Management, IV European Waste Forum, Milano, Italy. CIPA, Milán.

Andreottola, G., Bortolon, A., Dallago, L. y Ragazzi M. (2001). “A Comprehensive Study on MSW Baling as a Pre-treatment to Waste-to-Energy Plants". In Christensen, T.H., Cossu, R. y Stegmann, R. (eds). Sardinia 2001, Eighth International Waste Management and Landfill Symposium Cagliari, CISAEnvironmental Sanitary Engineering Centre, Cagliari, Italy. Sardinia, Italy, pp. 361-370.

Ansbjer, J; Hogland, W; Tamaddon F. (1995). Storage of Waste Fuels With Baling Technique. ISWA Times No. 3. Barradas, A. (2009). Planificación de la gestión integral de residuos sólidos municipales: guía metodológica para Países en Desarrollo. GYTSU. Recuperado de: http://oa.upm.es/1944/

CONAPO. (2010). La situación demográfica de México 2010. Recuperado de: http:// http://www.conapo.gob.mx/es/CONAPO/La_Situacion_Demografica_de_Mexico_2010

Costemalle, B. (1997). Elyo et EDF Stockent en Balles. Décision Environnement, 15.

Field, B. (1995). Economía ambiental: una introducción. Colombia: McGraw Hill

García, J. (2013). 48 camiones recogen basura de 616 colonias. Milenio, Diario de Tampico. Recuperado de: http://www.milenio.com/region/camiones-recogen-basura-colonias_0_204579895.html

Gasso, S. y Baldasano, JM. (2000). Evaluación del vertido de RSU en forma de pacas compactadas y empacadas con plástico. Residuos: Revista Técnica. 10 (52), 66- 73.

Goddard, H. C. (1995). The Benefits and Costs of Alternative Solid Waste Mana- gement Policies. Resources, Conservation and Recycling, 13, 183-213. https://doi.org/10.1016/0921-3449(94)00021-V

Henry, G. y Heinke, G. (1999): Ingeniería Ambiental. México: Prentice Hall y Pearson.

H. Congreso del Estado de Tamaulipas. (2016). Ley de Equilibrio Ecológico y Protección al Ambiente del Estado de Tamaulipas, 1992. Decreto No. $162 . \quad$ Recuperado de: http://www.tamaulipas.gob.mx/desarrollorural/wp-content/uploads/sites/6/2016/11/ley-delequilibrio-ecologico-y-proteccion-al-ambiente-del-estado-de-tamaulipas-1.pdf

Hernández, E. (2010). El problema de la vivienda marginal en México. El caso de los asentamientos humanos periféricos en el Sur de Tamaulipas, México. (Tesis doctoral), Barcelona: Universitat de Barcelona.

Hogland, W. (1998). Baled waste fuel at a thermal power station in Umea, Northern Sweden. 5th Polish-Danish Workshop on Biofuels, Starbienino: Technical University of Gdansk Poland.

INEGI. (2010). Censos de Población y Vivienda 2000 y 2010. Recuperado de: http://www.inegi.org.mx/est/contenidos/Proyectos/ccpv/default.aspx

Nammari, D., Mathiasson, L., Martensson L., Marques, M., Thöneby, L. y Hogland, W. (2007). Emissions from baled municipal solid waste: II effects of different treatments and baling techniques on the emission of volatile organic compunds. Waste Management and Research, 25(2), 109-118. DOI: $10.1177 / 0734242 \times 07071132$

ONU. (2007). Centro de Noticias ONU. Recuperado de: http://www.un.org/spanish/News/story.asp?newsID=9007\&criteria1=\#.WSZgHVePfIM 


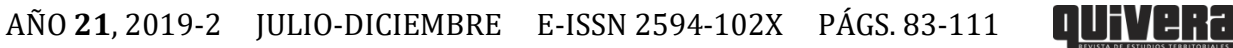

OPS-AIDIS-BID. (2010). Informe de la Evaluación regional del manejo de residuos sólidos en América Latina y el Caribe 2010. Recuperado

de: http://www6.iadb.org/Residuos/informacion/InfoPais.bid;jsessionid=8E7951C4F959A1349C26F996 04F2C2B1

Restrepo I., Bernache, G. y William, R. (1991). Los demonios del consumo. Basura y Contaminación. México: Centro de Ecodesarrollo.

Robles F, Gourgon R. (1999). Effect of baling on the behaviour of domestic wastes: Laboratory Study on the role of $\mathrm{pH}$ in Biodegradation, Bioresearch Technology, 69(1), 15-22. https://doi.org/10.1016/S09608524(98)00176-X

Rojas C. y Corona Z. (2008). Urban Observatories opportunities for environmental monitoring: Solid Wastes, Waste Management. 28(1). DOI: 10.1016/j.wasman.2008.04.008

SEMARNAP. (1996). Programa de medio ambiente 1995-2000. Recuperado de: http:/ / dof.gob.mx/nota_detalle.php?codigo=4878450\&fecha=03/04/1996

SEMARNAT. (2010). Informe de la situación del Medio Ambiente. Recuperado de: http://app1.semarnat.gob.mx/dgeia/informa_2008

SEMARNAT. (2012). Sistema de Información Nacional para la Gestión Integral de los Residuos (SINGIR). Recuperado de: http://app1.semarnat.gob.mx/dgeia/indicadores14/conjuntob/indicador/04_residuos/4_2.html.

Sieger, E. y Kewitz, H. (1997). “Application of Baling Technology for Temporary Storage of Household Waste”. En: Christensen, T. H., Cossu, R., Stegmann, R. (eds). Sardinia 97, the Sixth International Landfill Cagliari, Sardinia, Italy. 457-462.

Tamaddon, F., Hogland, W. y Kjellberg, J. (1995). Storage of waste-fuel by baling technique. Lund, Sweden: Lund University, Bala Press AB.

Tsagas, F., Petalas, A., Markidis, I., Tsakmakis, I., Grigoropoulos, N. y Dermatas, D. (2009). Baling- wrapping tchenology and MSW Management: Insights from a Pilot cases Study in Alexandroupolis, Greece. $11^{\circ}$ International Conference on Environmental Science and Technology. Chania, Crete, Creece. 953- 960.

United Nations. (2000). World Urbanization Prospects: the 1999 Revision, Data, Tables and Highlights. United. Nations, Population Division, ESA/P/WP.161, New York.

UNED. (2003). Gestión de residuos sólidos. Recuperado de: http://www2.uned.es/biblioteca/rsu/pagina3.htm

Velázquez, A. (2006). Gestión ambiental y tratamiento de residuos sólidos urbanos. Propuesta para la Zona Metropolitana de Guadalajara a partir de las experiencias de la Unión Europea (Tesis doctoral), Madrid: Universidad Complutense de Madrid. 